\title{
Mechanical forcing of the North American monsoon by orography
}

\author{
William Boos ( $\nabla$ william.boos@berkeley.edu ) \\ University of California, Berkeley \\ Salvatore Pascale \\ University of Bologna
}

\section{Physical Sciences - Article}

Keywords: monsoon, rainfall, global climate change

Posted Date: May 26th, 2021

DOI: https://doi.org/10.21203/rs.3.rs-514304/v1

License: (c) (i) This work is licensed under a Creative Commons Attribution 4.0 International License. Read Full License

Version of Record: A version of this preprint was published at Nature on November 24th, 2021. See the published version at https://doi.org/10.1038/s41586-021-03978-2. 


\title{
Mechanical forcing of the North American monsoon by orography
}

\author{
William R. Boos ${ }^{1,2, *}$ and Salvatore Pascale ${ }^{3}$ \\ ${ }^{1}$ Department of Earth and Planetary Science, University of California, Berkeley, USA \\ ${ }^{2}$ Climate and Ecosystem Sciences Division, Lawrence Berkeley National Laboratory, USA \\ ${ }^{3}$ Department of Physics and Astronomy, University of Bologna, Italy \\ *billboos@alum.mit.edu
}

\section{\& ABSTRACT}

The core of the North American monsoon consists of a band of intense rainfall along the west coast of Mexico ${ }^{1,2}$ and is commonly thought to be caused by thermal forcing from both land and the elevated terrain of that region ${ }^{3-5}$. Here we use observations, a global climate model, and stationary wave solutions to show that this rainfall maximum is instead generated when Mexico's Sierra Madre mountains mechanically force an adiabatic stationary wave by diverting extratropical eastward winds toward the equator; eastward, upslope flow in that wave lifts warm and moist air to produce convective rainfall. Land 9 surface heat fluxes do precondition the atmosphere for convection, particularly in summer afternoons, but even if amplified are insufficient for producing the observed rainfall maximum. These results, together with dynamical structures in observations and models, indicate that the core monsoon should be understood as convectively enhanced orographic rainfall in a mechanically forced stationary wave, not as a classic, thermally forced tropical monsoon. This has implications for the response of the North American monsoon to past and future global climate change, making trends in jet stream interactions with orography of central importance.

\section{Introduction}

Tropical monsoons occur when a surface of low heat capacity transfers the energy of intense summer solar radiation to the overlying atmosphere, creating thermally direct, precipitating flow. Such circulations supply water to billions of people and set the climate of large swaths of Earth's surface. The North American monsoon (NAM) is commonly viewed in this paradigm, being a low-latitude summer circulation crucial for the hydrology of western Mexico and the southwestern US ${ }^{1,2,6,7}$.

As in many tropical regions, North American orography alters the simple description of monsoon flow provided above. The core NAM consists of a narrow tongue of high precipitation stretching over 1,000 km north-south along the western side of the Sierra Madre Occidental (SMO) mountains (Fig. 1a). Drier conditions lie east of this precipitation maximum, in central Mexico and Texas, and atmospheric subsidence occurs to the west-northwest due to baroclinic Rossby waves forced by the latent heating ${ }^{8-10}$.

The mechanisms that produce this strong organization of NAM precipitation around orography remain unclear. Early global climate model (GCM) simulations showed that NAM rainfall decreases greatly when mountains are flattened globally ${ }^{11}$. Some argue that this occurs because sensible heat fluxes from orography into elevated levels of the atmosphere cause NAM rainfall ${ }^{3}$, drawing water vapor from the Gulf of California up SMO slopes to condense and precipitate ${ }^{2,12,13}$. The high-amplitude diurnal cycle of precipitation in the NAM has also been taken to suggest the importance of orographic thermal forcing. Shallow convection begins around noon over SMO peaks and deep convection follows a few hours later on the western slopes ${ }^{14}$. Near-surface air flows upslope during the day and downslope at night ${ }^{15,16}$, as expected for a sea breeze or mountain-valley breeze driven by solar heating. Despite the prominence of this diurnal cycle, horizontal moisture fluxes produced by transients (e.g., diurnally reversing sea breeze circulations) are an order of magnitude smaller in the core NAM than those produced by seasonal mean winds ${ }^{16}$. Thus, sea breeze circulations are observationally striking in the NAM, but their winds average to zero over 24 hours; core NAM precipitation must be controlled by the forcings that produce seasonal mean flow.

The mechanical, rather than thermal, effects of orography are known to drive the summer circulation east and northeast of the NAM, in the central US. A GCM and stationary wave model were used to show that the eastern Sierra Madre deflect trade winds northward to become the Great Plains low level jet ${ }^{17}, 18$, which transports water into the central US from the Gulf of Mexico but is not traditionally seen as a main NAM component. Some authors ${ }^{19}$ have considered orographic elevated heating and orographic blocking of zonal winds to both be plausible NAM causes, but models integrated at resolutions fine enough to resolve the SMO and core $\mathrm{NAM}^{20-22}$ have not been used to distinguish between these possibilities.

Our goal is to determine the mechanisms that cause the intense rainfall maximum in the core NAM. Is it generated primarily 
by a thermodynamic forcing (e.g. elevated heating) or a mechanical one (mechanical blocking)? Given the prior finding that time-mean vertically integrated moisture flux convergence in the core NAM is produced by time-mean winds ${ }^{16}$, this task amounts to determining the cause of the seasonal-mean eastward, upslope flow over the SMO.

\section{Net response to orography}

We integrate a high-resolution $\left(0.25^{\circ}\right.$-grid spacing) GCM twice: once with observed orography (Control) and again with surface height set to zero over nearly all of Mexico (FlatMex). This GCM, which uses prescribed sea surface temperature (SST), produces a realistic seasonal cycle and spatial pattern of NAM precipitation and wind in the Control run (Fig. 1a, b and Supplementary Figs. S1-S3; the model has a positive precipitation bias but its climatology falls in the range of observed interannual variability). The model resolves the SMO as a $\sim 3 \mathrm{~km}$-high ridge along Mexico's west coast, and reproduces observed eastward low-level winds extending roughly $1000 \mathrm{~km}$ west of that ridge (Fig. 1a, b). This wind distribution is suggestive of the midlatitude eastward jet being deflected toward the equator by the SMO; the broader North American cordillera is known to deflect the jet in such a stationary wave ${ }^{17}$, but the equatorial part of that wave has not previously been argued to play a role in the NAM, nor has it been adequately resolved in stationary wave models of the region.

We obtain the net response to all dynamic and thermodynamic effects of Mexico's orography by subtracting the FlatMex state from the Control. Nearly all core NAM precipitation is caused by local orography, with the rainfall maximum on Mexico's west coast disappearing in the FlatMex state despite the continued land surface thermal forcing (Fig. 1c). Without the SMO, westward trade winds span most of Mexico, separating two zones of eastward flow: one in the extratropics and another in the oceanic intertropical convergence zone (ITCZ) south of Mexico (near $15^{\circ} \mathrm{N}$ ). The region of high near-surface moist static energy (MSE), which in observations and the Control is confined to the Gulf of California and the Gulf of Mexico, expands inland to cover central Mexico when orography is flattened (Fig. 1d; surface air MSE is hereafter written $h_{s}$ and expressed in temperature units through normalization by the specific heat of air). In the FlatMex state, the distributions of $h_{s}$, precipitation, and wind behave as expected for tropical monsoons, with peak rainfall and low-level eastward flow on the equatorial side of the high- $h_{s}$ region $^{23,24}$.

The wind and $h_{s}$ response to the SMO suggests that core NAM precipitation is not forced primarily by orographic elevated heating, which would work by driving the overlying atmospheric column toward a higher-energy state than it would realize over the same surface at sea level ${ }^{25}$. The dynamical response to tropical heatings typically includes poleward flow through the heated region, in Sverdrup balance, with a low-level cyclone to the west ${ }^{26,27}$. Instead, we see anomalous eastward flow over the orographic forcing, with a low-level cyclone to the north and anticyclonic flow to the southwest (Fig. 1d). Orography decreases local $h_{s}$ over the SMO and continental Mexico, whereas orographic elevated heating would increase it ${ }^{25}$. However, since much of this reasoning employs comparisons with previous idealized solutions that might be complicated by strong background flows, we now systematically assess the response to separate mechanical and thermal forcings.

\section{Mechanically forced response}

We estimate the response to the mechanical influence of orography with a stationary wave model that has been used to study the Great Plains low-level jet ${ }^{17}$ and other orographically influenced circulations ${ }^{28,29}$, but integrated at finer resolution than used previously (see Methods). We impose as a basic state the three-dimensional summer-mean flow from the FlatMex GCM, then use this model to find the adiabatic response to Mexico's orography (the forcing is the Control-FlatMex surface height anomaly).

This mechanically forced response consists of a meridional dipole in low-level vorticity, with a cyclone over much of the western US and an anticyclone southwest of Mexico (Fig. 2c). The dynamical structure strongly resembles the GCM response (Control-FlatMex; Fig. 2a), even though the GCM also includes diabatic feedbacks and any orographic thermal forcing. The stationary wave includes anomalous eastward flow upstream of and over the SMO, with a vertical structure and amplitude similar to that of the net GCM response (Fig. 2b, d). This anomalous flow opposes the westward trade winds stretching across Mexico in the basic state. Between the surface and $\sim 850 \mathrm{hPa}$, the total flow (basic state plus stationary wave anomaly) is eastward upstream of and over the SMO western slopes (orange contours in Fig. 2b, d). The stationary wave thus produces the time-mean upslope wind over the western SMO that is observationally associated with moisture convergence and precipitation there $^{16}$.

The stationary wave is nonlinear, with isentropes (constant potential temperature surfaces) intersecting orography instead of bowing upward around it $^{8}$ (Fig. 2b, d; Supplementary Fig. S4 shows the linear response). Nevertheless, this response is straightforward to understand. When orography is high enough to block zonal winds, adiabatic flow, which in the time mean follows isentropes, must deviate northward or southward depending on where isentropes intersect the ground. In contrast with the basic state used in prior studies of flow perturbed by narrow orography ${ }^{8}$, peak temperatures lie near $38^{\circ} \mathrm{N}$, so isentropes over Mexico tilt downward to the north, intersecting the ground over the southwestern US (Fig. 2a, c, and Supplementary Fig. S5). 
Adiabatic zonal flow must thus ascend and turn southward as it encounters the SMO, because northward flow is blocked as it follows isentropes into the ground. Lower-resolution stationary wave solutions have a weaker anticyclone south of Mexico and give greater prominence to the Great Plains low-level jet (Supplementary Fig. S6), perhaps explaining why orographic mechanical forcing has previously been more closely associated with that circulation ${ }^{17}$.

\section{Seasonal and diurnal thermodynamic maxima}

How do we reconcile observations of a strong diurnal cycle of precipitation in the core NAM ${ }^{14-16}$ with evidence that upslope flow there is produced by a stationary wave? Moist convection requires both a reservoir of convective available potential energy (CAPE) and, typically, some lifting to overcome convective inhibition or release conditional instability. CAPE generally increases with $h_{s}{ }^{30,31}$, and high time-mean $h_{s}$ lies over the warm Gulf of California and Gulf of Mexico (Fig. 1d). However, maximum $h_{s}$ is achieved in late afternoon over western SMO slopes, at least in one observational estimate (Fig. 3a). The strong diurnal cycle of $h_{s}$, particularly prominent over elevated terrain (Fig. 3b), is caused by solar heating of land, which increases $h_{s}$ through surface enthalpy fluxes (there is observational uncertainty in the magnitude of the $h_{s}$ maximum over the western SMO, but all estimates show high $h_{s}$ there with a large diurnal cycle). Thus, a warm and moist air layer from the Gulf of California flows eastward at low levels in the mechanically forced stationary wave, and its MSE is increased further by daytime surface heat fluxes while its temperature drops adiabatically due to upslope flow. In a convectively stable atmosphere this scenario would produce large-scale, stratiform condensation, but nonzero CAPE allows convection to occur. Prior work ${ }^{19}$ showed that the observed CAPE distribution does not explain why NAM precipitation favors the west coast of Mexico versus the east coast; release of CAPE through upslope flow in the stationary wave resolves this issue.

These effects can be synthesized by examining the seasonal cycle of $h_{s}$ and near-surface zonal wind averaged in and upstream of the core NAM region, respectively. Upslope flow peaks in spring, before the observed rainy season, but $h_{s}$ is low then so ample convective precipitation is not produced (Fig. 3c). Peak precipitation occurs a few months later when upslope flow is still strong and $h_{s}$ has increased to its summer peak. Flattening Mexico's orography produces a slight increase in summer $h_{s}$, presumably because orography blocks the inland penetration of warm and moist oceanic air, yet NAM precipitation decreases greatly as upslope flow is reduced (Fig. 1c). The seasonality of NAM precipitation thus seems to arise from the seasonal cycle in $h_{s}$ (and CAPE) but, consistent with CAPE being a necessary but insufficient condition for convection, mechanically forced ascent in the stationary wave is needed to turn that thermodynamic seasonal cycle into rainfall.

The $h_{s}$ distribution (Fig. 3a) also illustrates the deviation of the spatial structure of the NAM from that of a classic tropical monsoon. In the latter we expect peak rainfall and peak low-level eastward wind on the equatorial side of the $h_{s}$ maximum ${ }^{23,24}$. Instead, we observe peak NAM rainfall slightly east of (or even directly over) the peak $h_{s}$, and low-level eastward winds west of the peak $h_{s}$. This suggests that the thermally forced tropical monsoon in the North American region consists of the oceanic precipitation maximum just south of Mexico, which would exist without Mexico's orography (Fig. 1c); southward deflection of prevailing extratropical winds by the North American cordillera (including the SMO) superimposes on that tropical monsoon the intense band of rainfall along Mexico's west coast.

\section{Response to a pure thermal forcing}

We now show that if the core NAM were driven primarily by a thermal forcing, it would have a dynamical structure distinct from that in observations. We conduct a third GCM integration with the albedo of the surface that was flattened (most of Mexico) reduced to 0.05 (FlatMexLowAlb). This provides a strong thermal forcing, with land albedo in much of the NAM region reduced below that of open ocean, yielding a local increase of about $20 \mathrm{~W} \mathrm{~m}^{-2}$ in the net energy input to the atmosphere (NEI; the sum of radiative and surface turbulent fluxes into each atmospheric column; Fig. 4a). In response, the high $h_{s}$ region expands poleward and the oceanic precipitation maximum follows, expanding inland (compare Figs. $4 \mathrm{~b}$ and 1c, d). Anomalous low-level poleward flow over the region in which the albedo forcing was applied is consistent with the Sverdrup balance achieved in the linear response to tropical thermal forcings ${ }^{26}$. As expected for a thermally forced tropical monsoon ${ }^{23,24}$, peak rainfall lies on the equatorial side of the high- $h_{s}$ region, and precipitation increases by about $2 \mathrm{~mm} \mathrm{day}{ }^{-1}$ over the broad region of the albedo forcing (Fig. 1c). In FlatMexLowAlb, there is no precipitation maximum along Mexico's west coast and no eastward flow extending $1000 \mathrm{~km}$ west of the SMO.

These GCM simulations also suggest that core NAM rainfall is not produced by rectification of the diurnal cycle of precipitation to produce seasonal-mean heating, a hypothesis proposed to explain the enhancement of time-mean precipitation over small islands ${ }^{32}$ although not explicitly raised for the NAM. If such a mechanism operated in the NAM, it would need to have an effect stronger than that achieved by the increase in $h_{s}$ produced in the FlatMexLowAlb model (Fig. 4) and be confined to the western slopes of the SMO; it would not explain how the SMO produces eastward low-level winds stretching $1000 \mathrm{~km}$ west of Mexico. 


\section{Discussion and conclusions}

The NAM is commonly categorized as a thermally forced tropical monsoon. Although one early study stated that it was difficult to determine whether mechanical or thermal effects of orography dominated in forcing the $\mathrm{NAM}^{19}$, most previous work has described the NAM as either $(i)$ similar to though smaller in scale than the South Asian monsoon ${ }^{15}$, with a central role played by elevated plateau heating ${ }^{3}$, or (ii) caused by land-ocean thermal contrast ${ }^{4,8,33}$.

We found that a mechanically forced stationary wave produces the seasonal-mean upslope flow associated in prior work ${ }^{13,16}$ with the water vapor convergence needed to sustain core NAM rainfall. Such stationary waves dominate North American climate in winter ${ }^{34}$, but in summer they have been identified primarily with the Great Plains low level jet ${ }^{17}$. Stationary waves are also forced by the Rockies and other parts of the North American Cordillera, and Baja peninsula orography seems to steer eastward winds toward the equator (Fig. 1c). However, our results suggest that core NAM precipitation requires the SMO, which produce eastward, upslope flow in the region of high $h_{s}$.

Mechanically forced stationary waves will be modified in the real atmosphere by moist convective heating, but the resemblance between horizontal winds in the adiabatic stationary wave solutions and in the moist GCM suggests this has only a modest effect on horizontal flow (Fig. 2). Upward motions will be amplified by moist convection; such amplification has been represented using various forms of a reduced effective static stability for convectively coupled equatorial waves ${ }^{35}$, transient off-equatorial vortices ${ }^{36}$, and extratropical precipitation extremes ${ }^{37}$, but a similar theory for moist convective amplification of orographic upslope flow has not been developed.

These findings have implications for past and future NAM variability, placing new emphasis on the jet stream and trade winds, and their interaction with orography. Changes in the jet stream and trade winds may have been of central importance for NAM changes in paleoclimates. Accurate dynamical forecasts of NAM rainfall will require models with an unbiased jet stream, in addition to resolutions fine enough to represent the SMO. Thermodynamic controls on convection, long thought to dominate NAM rainfall, are important, but their representation in models should be evaluated in terms of how they affect convection in upslope flow. In contrast, surface conditions and convective stability over central Mexico may primarily affect the low amounts (1-2 $\left.\mathrm{mm} \mathrm{day}^{-1}\right)$ of local summer rainfall received there. Finally, global climate change may alter the NAM through changes in the extratropical jet stream and through changes in convective stability in regions of upslope flow, rather than through its influence on more general land-ocean thermodynamic contrasts.

\section{Methods}

\subsection{Observations}

We obtain estimates of Earth's atmospheric state from ERA5, the fifth-generation atmospheric reanalysis from the European Centre for Medium-Range Weather Forecasts ${ }^{38-40}$. For years 1979-2019, we use ERA5 surface air temperature, surface air dewpoint (which we convert to specific humidity to calculate $h_{s}$ ), surface height, and 100-meter zonal wind. We also obtain surface air temperature, surface air dewpoint, and surface height from the Modern-Era Retrospective analysis for Research and Applications, Version 2 (MERRA2) ${ }^{41}$. Precipitation estimates are drawn from the Global Precipitation Measurement Mission (GPM) Integrated Multi-satellitE Retrievals for GPM (IMERG), Final Precipitation L3 Daily 0.1 degree $\times 0.1$ degree V06 product (GPM_3IMERGDF) ${ }^{42}$. We averaged years 2001-2020 to obtain the precipitation climatology shown in Fig. 1a. Plots of surface height use estimates from the ETOPO1 global relief model ${ }^{43,44}$ at 1 arc-minute resolution; surface height used in calculating reanalyzed $h_{s}$ is taken from ERA5 and MERRA2. All quantities are averaged July-September.

Surface air MSE is also computed for stations along a transect near $28^{\circ} \mathrm{N}$ using observations of temperature, specific humidity, and height from the North American Monsoon GPS Transect Experiment $2013^{45}$ (measurements collected JuneSeptember 2013), and the 2017 North American Monsoon GPS Hydrometeorological Network ${ }^{46}$ (hereafter referred to as GPS Hydromet 2017, measurements collected June-September 2017), which uses some of the permanent observation sites of the Trans-boundary, Land and Atmosphere Long-term Observational and Collaborative Network (TLALOCNet) ${ }^{47}$. Data from the GPS Transect Experiment 2013 are available every minute while GPS Hydromet 2017 are at 5-minute intervals. We compute $h_{s}$ for all minutes within the 01 UTC and 13 UTC hours, corresponding to late afternoon and early morning in local time, respectively. We average for all days from July through September for both datasets, and retain only those stations for which there are less then ten days of missing data. Data for stations within $0.5^{\circ}$ latitude of $28^{\circ} \mathrm{N}$ were used for the transect.

\subsection{Models}

\subsubsection{Global climate model}

Simulations were performed using the Community Atmospheric Model, version 5.1 (CAM5) ${ }^{48}$ coupled to the Community Land Model, version $4^{49}$, within the software infrastructure of the Community Earth System Model (CESM) version 2.1.3. We use the finite-volume dynamical core, which is typically configured with a horizontal resolution of $0.9^{\circ}$ (latitude) by $1.3^{\circ}$ (longitude); to better resolve the topography of the NAM region, we use a global horizontal resolution of $0.23^{\circ} \times 0.31^{\circ}$ (i.e., 
approximately $25 \mathrm{~km}$ at the equator) with 30 vertical levels. We use the Sea ICE model (CICE) version 5 with prescribed ice cover and prescribed cyclic sea surface temperature (SST) from the year 2000. This model configuration is largely the same as that used in projections of the future behavior of tropical cyclones ${ }^{50,51}$, and prior work has shown that the finer horizontal resolution used here improves the representation of the NAM in CAM5 ${ }^{22}$.

As discussed in previous work ${ }^{20,21,52}$, climate models with relatively coarse horizontal resolution fail to resolve features like the Gulf of California and the Sierra Madres, thereby misrepresenting key NAM processes such as Gulf of California moisture surges ${ }^{2,53,54}$, land-sea contrast ${ }^{55}$, and mechanical flow-blocking by orography ${ }^{56}$. Furthermore, SST biases in coupled GCMs can have a detrimental impact on simulation of the NAM, biasing its seasonal evolution to produce a late withdrawal and thus an overly wet late summer and autumn ${ }^{57-59}$. Therefore, using a high resolution configuration with climatological SST reduces the model's bias and brings the regional circulation closer to observations (Supplementary Figs. S1-S3).

To assess the influence of elevated terrain on the core NAM, we integrate the model with standard orography (Control) and again with flattened orography over most of Mexico (FlatMex). In the integration with flattened orography over Mexico, we set both the surface height and the subgrid-scale standard deviation of orography to zero within a quadrilateral having these vertices: $\left(33^{\circ} \mathrm{N}, 245^{\circ} \mathrm{E}\right),\left(29^{\circ} \mathrm{N}, 265^{\circ} \mathrm{E}\right),\left(15^{\circ} \mathrm{N}, 257^{\circ} \mathrm{E}\right)$, and $\left(15^{\circ} \mathrm{N}, 265^{\circ} \mathrm{E}\right)$. Orography on the Baja Peninsula is unaltered (it lies outside this quadrilateral). To avoid creating a high vertical wall of orography at the northern edge of this quadrilateral, where Mexico's orography joins the greater North American cordillera, the surface height is set to decrease linearly to zero over $2^{\circ}$ of latitude immediately south of the northern edge of the quadrilateral; the same procedure is used for the subgrid-scale standard deviation of orography. To help distinguish between the thermal and mechanical influence of orography, we conduct a third integration in which the surface albedo of the flattened land is set to 0.05 (FlatMexLowAlb); this is done for both the direct and diffuse albedo by altering the land model (CLM4). To be clear, this third integration has both flattened orography over Mexico and reduced surface albedo, in an attempt to impose an enhanced thermal forcing without the mechanical effects of orography. All three of these model configurations are run for 11 years of simulated time, with the last 10 years analyzed.

To understand how orography deflects the midlatitude westerlies toward the equator and then forces convection through upslope flow (Fig. 1), we analyze the time-mean zonal wind on a terrain-following level located within a typical subcloud layer (the atmospheric layer that lies below cloud base). For ERA5 we choose the level $100 \mathrm{~m}$ above Earth's surface, while for the GCM we use the horizontal wind on the third model level above the surface (level 957.5).

\subsubsection{Stationary wave model}

To isolate the mechanical influence of Mexico's orography on the atmospheric circulation we use a fully nonlinear stationary wave model. The model was introduced by Ting and Yu $(1998)^{60}$, and solves the primitive equations in terms of vorticity, divergence, temperature, and the logarithm of surface pressure, using spherical harmonics ${ }^{29,61,62}$. Important distinctions with the GCM are that the stationary wave model $(i)$ solves these equations for anomalies relative to a specific three-dimensional basic state and (ii) is adiabatic aside from a 15-day Newtonian relaxation of temperature toward the basic state, as used in prior work $^{34,60}$. Transients, such as midlatitude baroclinic instabilities, are suppressed using drag and scale-selective diffusion. Specifically, interior Rayleigh drag on the anomalies is imposed with a 15-day time scale, with surface drag represented by gradually reducing this time scale to 0.3 days over the lowest 4 levels. Biharmonic diffusion with a coefficient of $10^{17} \mathrm{~m}^{4}$

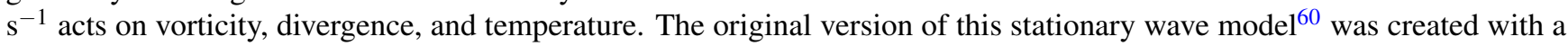
rhomboidal truncation at wavenumber 15 (R15 spectral resolution) and 12 vertical levels. Later work integrated the model at $\mathrm{R} 30$ resolution with 14 vertical levels ${ }^{28}$ and R30 resolution with 24 vertical levels ${ }^{29}$. We enhanced the resolution to R63 with 24 levels, based on code supplied by Isla Simpson.

The model was forced by imposing Mexico's orography on a basic state obtained by time-averaging the summer atmospheric state from the GCM without that orography. Specifically, we obtain the basic state by taking the 10-year July-September average atmospheric state from the FlatMex GCM run, and use the surface height difference between the Control and FlatMex GCM runs as the forcing. The stationary wave model nears a steady state after about 20 days, and is run for 90 days of simulated time with the last 20 used for analysis.

\section{Data Availability}

The ERA5 monthly averaged data by hour of day were downloaded from the Copernicus Climate Change Service Climate Data Store (identifiers cited in Methods). MERRA-2 and GPM data were downloaded from the NASA Goddard Earth Sciences Data and Information Services Center (GES DISC; identifiers cited in Methods). ETOPO1 data were downloaded from the National Centers for Environmental Information at NOAA, identifiers cited in Methods). David K. Adams provided access to GPS Hydromet 2017, TLALOCNet, and GPS Transect Experiment 2013 data. 


\section{Code Availability}

The CESM model, which is supported primarily by the National Science Foundation, was obtained from https://www . cesm. ucar. edu. Isla Simpson provided code for the stationary wave model, the original version of which was written by Mingfang Ting and Linhai Yu.

\section{References}

1. Douglas, M. W., Maddox, R. A., Howard, K. \& Reyes, S. The Mexican Monsoon. J. Clim. 6, 1665-1677 (1993).

2. Adams, D. K. \& Comrie, A. C. The North American Monsoon. Bull. Am. Meteorol. Soc. 78, 2197-2213, DOI: 10.1175/1520-0477(1997)078<2197:TNAM>2.0.CO;2 (1997).

3. Tang, M. \& Reiter, E. R. Plateau Monsoons of the Northern Hemisphere: A Comparison between North America and Tibet. Mon. Wea. Rev. 112, 617-637 (1984).

4. Vera, C. et al. Toward a unified view of the American monsoon systems. J. Clim. 19, 4977-5000, DOI: 10.1175/JCLI3896.1 (2006).

5. Mechoso, C. R., Robertson, A. W., Ropelewski, C. F. \& Grimm, A. M. The American Monsoon Systems: An Introduction. In Chang, C.-P., Wang, B. \& Lau, N.-C. (eds.) The Global monsoon system : research and forecast, chap. 13, 197-206, DOI: 10.7916/D8ST803T (WMO/TD- No. 1266; Tropical Meteorology Research Programme (TMRP) Report- No. 70, 2005).

6. Bryson, R. A. \& Lowry, W. P. Synoptic climatology of the Arizona summer precipitation singularity. Bull. Amer. Meteor. Soc. 36, 329-339 (1955).

7. Krishnamurti, T. N. Tropical east-west circulations during the northern summer. J. Atmos. Sci. 28, 1342-1347 (1971).

8. Rodwell, M. J. \& Hoskins, B. J. Subtropical Anticyclones and Summer Monsoons. J. Clim. 14, 3192-3211 (2001).

9. Shaffrey, L. C., Hoskins, B. J. \& Lu, R. The relationship between the North American summer monsoon, the Rocky Mountains and the North Pacific subtropical anticyclone in HadAM3. Q.J.R. Meteorol. Soc. 128, 2607-2622 (2002).

10. Saini, R., Barlow, M. \& Hoell, A. Is the North American monsoon self-limiting? Geophys. Res. Lett. 40, 4442-4447 (2013).

11. Broccoli, A. J. \& Manabe, S. The effects of orography on midlatitude Northern Hemisphere dry climates. J. Clim. 5, 1181-1201 (1992).

12. Stensrud, D., Gall, R., Mullen, S. \& Howard, K. Model climatology of the Mexican monsoon. J. Clim. 8, 1775-1794 (1995).

13. Schmitz, J. T. \& Mullen, S. L. Water vapor transport associated with the summertime North American monsoon as depicted by ECMWF analyses. J. Clim. 9, 1621-1634 (1996).

14. Nesbitt, S., Gochis, D. \& Lang, T. The diurnal cycle of clouds and precipitation along the Sierra Madre Occidental observed during NAME-2004: Implications for warm season precipitation estimation in complex terrain. J. Hydrometeorol. 9, 728-743 (2008).

15. Johnson, R. H., Ciesielski, P. E., McNoldy, B. D., Rogers, P. J. \& Taft, R. K. Multiscales variability of the flow during the North American Monsoon experiment. J. Clim. 20, 1628-1648, DOI: 10.1175/JCLI4087.1 (2007).

16. Berbery, E. Mesoscale Moisture Analysis of the North American Monsoon. J. Clim. 14, 121-137 (2001).

17. Ting, M. \& Wang, H. The Role of the North American Topography on the Maintenance of the Great Plains Summer Low-Level Jet. J. Atmos. Sci. 63, 1056-1068 (2006).

18. Wexler, H. A Boundary Layer Interpretation of the Low-level Jet. Tellus 13, 368-378 (1961).

19. Barlow, M., Nigam, S. \& Berbery, E. Evolution of the North American Monsoon System. J. Clim. 11, 2238-2257 (1997).

20. Collier, J. C. \& Zhang, G. J. Effects of increased horizontal resolution on simulation of the North American monsoon in the NCAR CAM3: An evaluation based on surface, satellite, and reanalysis data. J. Clim. 20, 1843-1861 (2007).

21. Pascale, S. et al. The impact of horizontal resolution on North American monsoon Gulf of California moisture surges in a suite of coupled global climate models. J. Clim. 29, 7911-7936, DOI: 10.1175/JCLI-D-16-0199.1 (2016).

22. Varuolo-Clarke, A. M., Reed, K. A. \& Medeiros, B. Characterizing the North American Monsoon in the Community Atmosphere Model: Sensitivity to Resolution and Topography. J. Clim. 32, 8355-8372 (2019). 
23. Privé, N. C. \& Plumb, R. A. Monsoon Dynamics with Interactive Forcing. Part II: Impact of Eddies and Asymmetric Geometries. J. Atmospheric Sci. 64, 1431-1442, DOI: 10.1175/JAS3917.1 (2007).

24. Nie, J., Boos, W. R. \& Kuang, Z. Observational evaluation of a convective quasi-equilibrium view of monsoons. J. Clim. 23, 4416-4428, DOI: 10.1175/2010JCLI3505.1 (2010).

25. $\mathrm{Hu}, \mathrm{S} . \&$ Boos, W. The physics of orographic elevated heating in radiative-convective equilibrium. J. Atmos. Sci. 74, 2949-2965 (2017).

26. Gill, A. E. Some simple solutions for heat-induced tropical circulation. Q. J. Royal Meteorol. Soc. 106, 447-462, DOI: 10.1002/qj.49710644905 (1980).

27. Rodwell, M. J. \& Hoskins, B. J. Monsoons and the dynamics of deserts. Q. J. Royal Meteorol. Soc. 122, 1385-1404, DOI: 10.1002/qj.49712253408 (1996).

28. Simpson, I. R., Seager, R., Shaw, T. A. \& Ting, M. Mediterranean summer climate and the importance of Middle East topography. J. Clim. 28, 1977-1996 (2015).

29. Simpson, I. R., Seager, R., Ting, M. \& Shaw, T. A. Causes of change in Northern Hemisphere winter meridional winds and regional hydroclimate. Nat. Clim. Chang. 6, 65-70 (2016).

30. Emanuel, K. A. Atmospheric Convection (Oxford University Press, 1994).

31. Sobel, a. H. \& Bretherton, C. S. Modeling tropical precipitation in a single column. J. Clim. 13, 4378-4392, DOI: 10.1175/1520-0442(2000)013<4378:MTPIAS > 2.0.CO;2 (2000).

32. Cronin, T. W., Emanuel, K. A. \& Molnar, P. Island precipitation enhancement and the diurnal cycle in radiative-convective equilibrium. Q. J. Royal Meteorol. Soc. 141, 1017-1034, DOI: 10.1002/qj.2443 (2015).

33. Higgins, R. W., Chen, Y. \& Douglas, A. V. Interannual variability of the North American warm season precipitation regime. J. Clim. 12, 653-680, DOI: 10.1175/1520-0442(1999)012<0653:ivotna>2.0.co;2 (1999).

34. Held, I. M., Ting, M. \& Wang, H. Northern winter stationary waves: Theory and modeling. J. Clim. 15, 2125-2144, DOI: 10.1175/1520-0442(2002)015<2125:NWSWTA>2.0.CO;2 (2002).

35. Emanuel, K. A., Neelin, D. J. \& Bretherton, C. S. On large-scale circulations in convecting atmospheres. Q. J. Royal Meteorol. Soc. 120, 1111-1143, DOI: 10.1002/qj.49712051902 (1994).

36. Nie, J., Shaevitz, D. A. \& Sobel, A. H. Forcings and feedbacks on convection in the 2010 Pakistan flood: Modeling extreme precipitation with interactive large-scale ascent. J. Adv. Model. Earth Syst. 8, 1055-1072, DOI: 10.1002/2016MS000663 (2016). 1603.01218.

37. Li, Z. \& O'Gorman, P. A. Response of Vertical Velocities in Extratropical Precipitation Extremes to Climate Change. J. Clim. 33, 7125-7139, DOI: 10.1175/JCLI-D-19-0766.1 (2020).

38. Hersbach, H. et al. The ERA5 global reanalysis. Q J R Meteorol Soc. 146, 1999-2049, DOI: 10.1002/qj.3803 (2020).

39. European Centre for Medium-Range Weather Forecasts. ERA5 Reanalysis (0.25 Degree Latitude-Longitude Grid). Res. Data Arch. at Natl. Cent. for Atmospheric Res. Comput. Inf. Syst. Lab. Updat. monthly. Accessed 30 Apr 2020. DOI: 10.5065/BH6N-5N20 (2019).

40. Hersbach, H. et al. ERA5 monthly averaged data on single levels from 1979 to present. Copernicus Clim. Chang. Serv. (C3S) Clim. Data Store (CDS). (Accessed on 25-Feb-2021) DOI: 10.24381/cds.f17050d7 (2019).

41. Gelaro, R. et al. The Modern-Era Retrospective Analysis for Research and Applications, Version 2 (MERRA-2). J. climate Volume 30, 5419-5454, DOI: 10.1175/JCLI-D-16-0758.1 (2017).

42. Huffman, G., Stocker, E., Bolvin, D., Nelkin, E. \& Tan, J. GPM IMERG Final Precipitation L3 1 day 0.1 degree x 0.1 degree V06. Ed. by Andrey Savtchenko, Greenbelt, MD, Goddard Earth Sci. Data Inf. Serv. Cent. (GES DISC), Accessed: 03 May 2021 DOI: 10.5067/GPM/IMERGDF/DAY/06 (2019).

43. NOAA National Geophysical Data Center. ETOPO1 1 Arc-Minute Global Relief Model. NOAA Natl. Centers for Environ. Information. Accessed 14 Jan 2021 (2009).

44. Amante, C. \& Eakins, B. ETOPO1 1 Arc-Minute Global Relief Model: Procedures, Data Sources and Analysis. NOAA Technical Memorandum NESDIS NGDC-24. Tech. Rep., National Geophysical Data Center, NOAA (2009). DOI: 10.7289/V5C8276M[14Jan2021].

45. Serra, Y. L. et al. The North American Monsoon GPS Transect Experiment 2013. Bull. Am. Meteorol. Soc. 97, 2103-2115 (2016). 
46. Pérez-Ruiz, E. R. et al. Landscape Controls on Water-Energy-Carbon Fluxes Across Different Ecosystems during the North American Monsoon. J. Geophys. Res. Biogeosciences 126, e2020JG005809, DOI: https://doi.org/10.1029/2020JG005809 (2021).

47. Cabral-Cano, E. et al. TLALOCNet: A Continuous GPS-Met Backbone in Mexico for Seismotectonic and Atmospheric Research. Seismol. Res. Lett. 89, 373-381, DOI: 10.1785/0220170190 (2018).

48. Neale, R. B. et al. Description of the NCAR Community Atmosphere Model (CAM 5.0). Ncar/Tn-464+Str DOI: 10.5065/D6N877R0. (2012).

49. Oleson, K. W. et al. Technical Description of version 4.0 of the Community Land Model (CLM). Tech. Rep., NCAR Tech. Note NCAR/TN-478+STR (2010).

50. Wehner, M. F. et al. Resolution Dependence of Future Tropical Cyclone Projections of CAM5.1 in the U.S. CLIVAR Hurricane Working Group Idealized Configuration . J. Clim. 28, 3905-3925, DOI: 10.1175/JCLI-D-14-00311.1 (2015).

51. Wehner, M. F., Reed, K. A., Loring, B., Stone, D. \& Krishnan, H. Changes in tropical cyclones under stabilized 1.5 and $2.0^{\circ} \mathrm{C}$ global warming scenarios as simulated by the Community Atmospheric Model under the HAPPI protocols. Earth Syst. Dynam. 9, 187-195, DOI: 10.5194/esd-9-187-2018 (2018).

52. Mo, K. C., Juang, H. M. H., Higgins, R. W. \& Song, Y. Impact of model resolution on the prediction of summer precipitation over the United States and Mexico. J. Clim. 18, 3910-3927, DOI: 10.1175/JCLI3513.1 (2005).

53. Hales, J. E. Surges of maritime tropical air northward over the Gulf of California. Mon. Wea. Rev. 100, 298-306 (1972).

54. Brenner, I. S. A surge of maritime tropical air-Gulf of California to the southwestern United States. Mon. Wea. Rev. 102, 375-389 (1974).

55. Turrent, C. \& Cavazos, T. Role of the land-sea thermal contrast in the interannual modulation of the North American Monsoon. Geophys. Res. Lett. 36, L02808 (2009).

56. Finch, Z. O. \& Johnson, R. H. Observational analysis of an upper-level inverted trough during the 2004 North American Monsoon Experiment. Mon. Wea. Rev. 138, 3540-3555 (2010).

57. Liang, X., Zhu, J., Kunkel, K. E., Ting, M. \& Wang, J. X. L. Do CGCMs simulate the North American monsoon precipitation seasonal-interannual variability? . J. Clim. 21, 4424-4448, DOI: 10.1175/2008JCLI2174.1 (2008).

58. Geil, K. L., Serra, Y. L. \& Zeng, X. Assessment of CMIP5 model simulations of the North American monsoon system. $J$. Clim. 26, 8787-8801 (2013).

59. Pascale, S. et al. Weakening of the North American monsoon with global warming. Nat. Clim. Chang. 7, DOI: 10.1038/nclimate3412 (2017).

60. Ting, M. \& Yu, L. Steady response to tropical heating in wavy linear and nonlinear baroclinic models. J. Atmos. Sci. 55, 3565-3582 (1998).

61. Ting, M. \& Held, I. M. The stationary wave response to a tropical SST anomaly in an idealized GCM. J. Atmos. Sci. 47, 2546-2556 (1990).

62. Ting, M. The stationary wave response to a tropical SST anomaly in an idealized GCM. J. Atmos. Sci. 51, 3286-3308 (1994).

\section{Acknowledgements}

This material is based on work supported by the U.S. Department of Energy, Office of Science, Office of Biological and Environmental Research, Climate and Environmental Sciences Division, Regional and Global Model Analysis Program, under Award DE-SC0019367. It used resources of the National Energy Research Scientific Computing Center (NERSC), which is a DOE Office of Science User Facility. This paper benefited from discussions with Quentin Nicolas, David Adams, Inez Fung, and John C. H. Chiang.

\section{Author contributions}

WRB conceived the study, devised and performed the GCM and stationary wave model integrations, and analyzed model output. SP assessed the GCM bias. Both authors analyzed observations and contributed to writing the manuscript. 


\section{Additional information}

Supplementary information is available in the online version of the paper. Reprints and permissions information is available online at www.nature.com/reprints. Correspondence and requests for materials should be addressed to WRB.

\section{Competing financial interests}

The authors declare no competing financial interests.
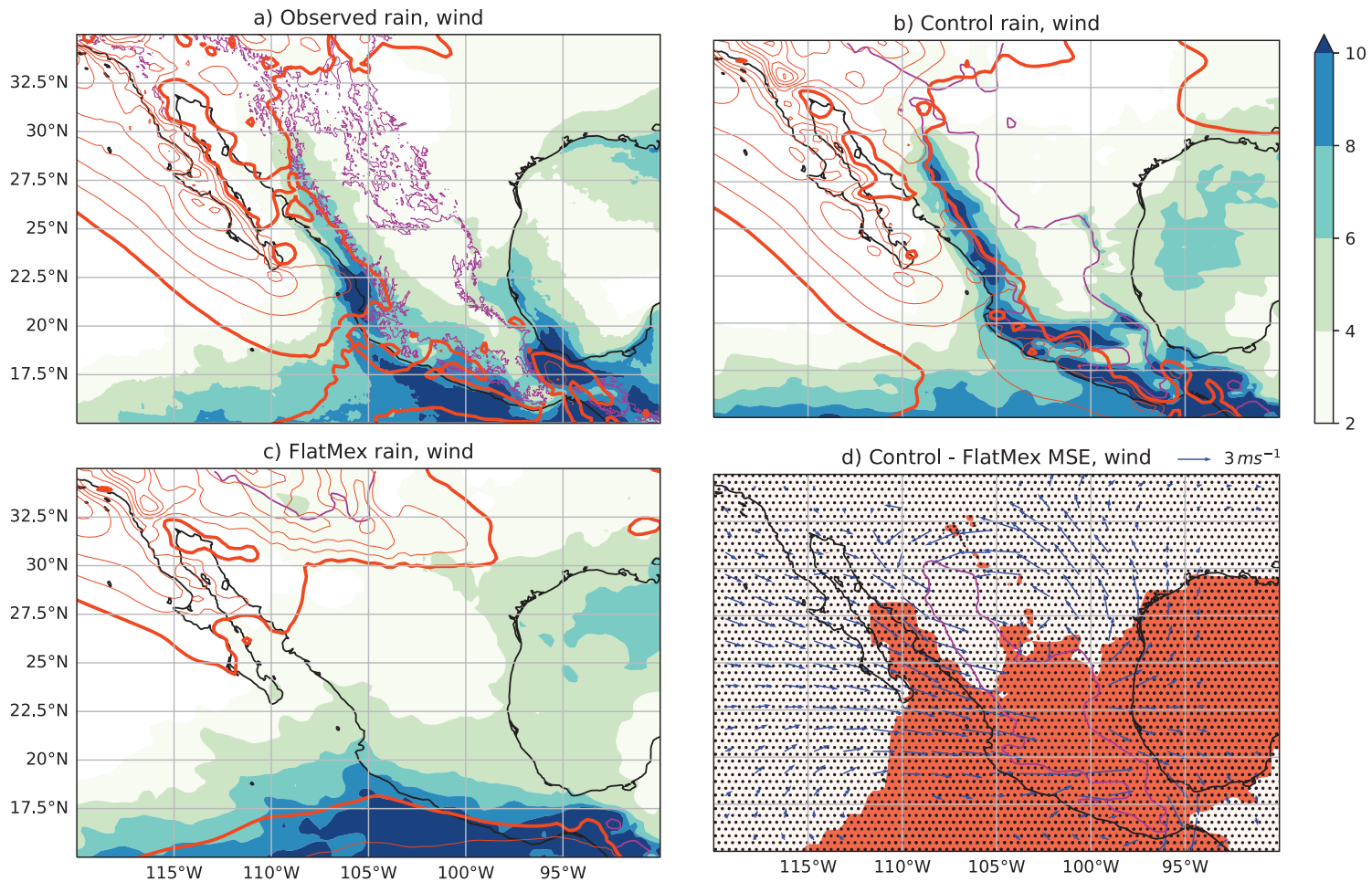

Figure 1. Influence of orography on rain and low-level wind. Summer precipitation (shading, $\mathrm{mm}^{\mathrm{day}}{ }^{-1}$ ) and near-surface eastward wind (orange contours, interval $1 \mathrm{~m} \mathrm{~s}^{-1}$, with the zero contour bold and negative values omitted) for (a) observations, (b) the control GCM, and (c) the GCM with flattened orography over Mexico. Panel (d) shows the anomalous 700 $\mathrm{hPa}$ horizontal wind (vectors) produced by Mexico's orography in the GCM, and the extent of the region with high surface air moist static energy (defined as a 2-meter value larger than $345 \mathrm{~kJ} \mathrm{~kg}^{-1}$ ) in the control model (black stippling) and the model with flattened orography over Mexico (red shading). Surface height of $1.5 \mathrm{~km}$ is contoured in magenta in all panels. 
a) GCM, 700.0 hPa streamfunction

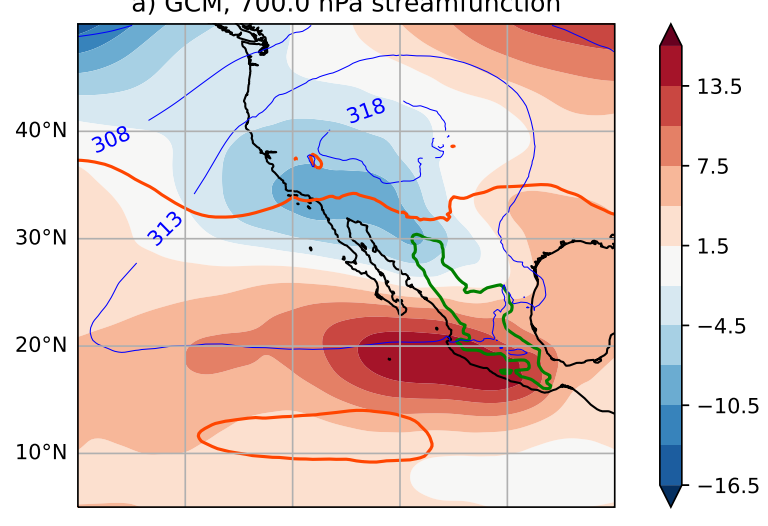

c) Stationary wave, $700.0 \mathrm{hPa}$ streamfunction

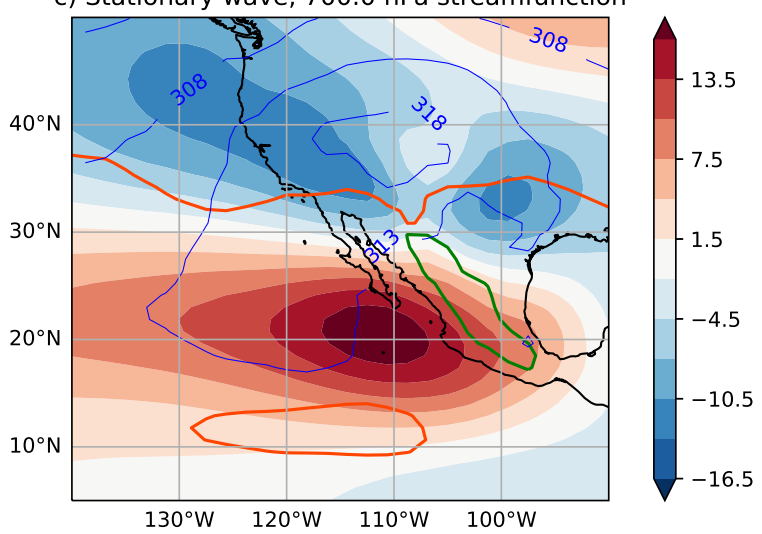

b) GCM, zonal wind, $26.0 \% \mathrm{~N}$

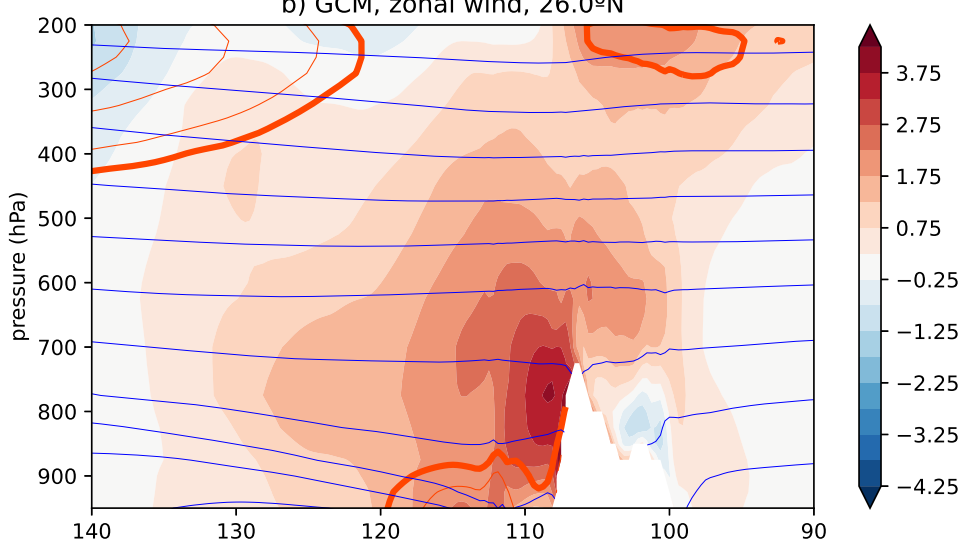

d) Stationary wave, zonal wind, $26.0 \% \mathrm{~N}$

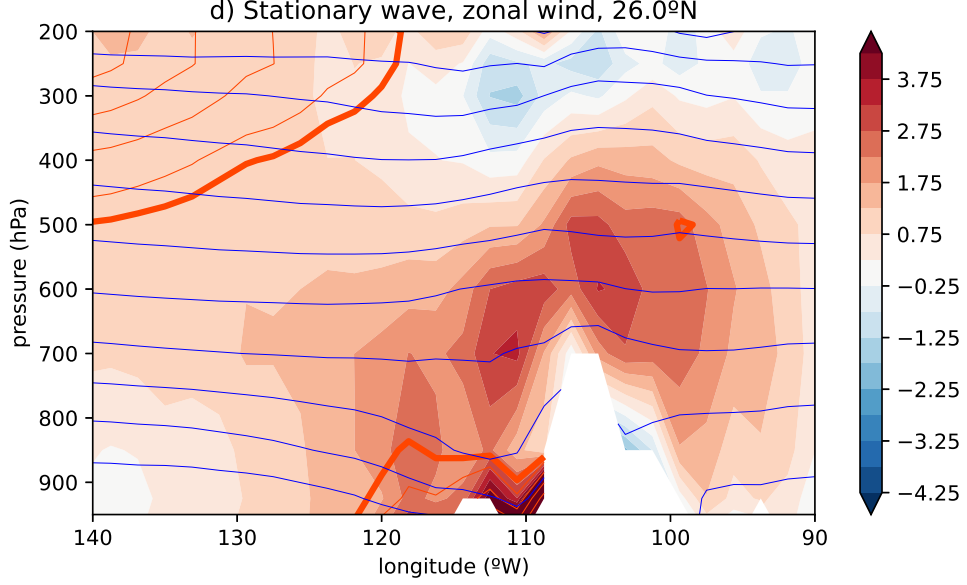

Figure 2. Generation of eastward flow across western Mexico by the mechanically forced stationary wave. Left panels show streamfunction of the anomalous $700 \mathrm{hPa}$ horizontal wind (shading, in meters; air flows clockwise around maxima) for (a) the Control-FlatMex GCM integrations and (c) the stationary wave model forced by the Control-FlatMex surface height (1.5 $\mathrm{km}$ surface height is contoured in green). The thick orange line is the zero contour of the basic state zonal wind, which near $35^{\circ} \mathrm{N}$ divides westward trade winds from prevailing eastward extratropical flow. Thin blue lines show $700 \mathrm{hPa}$ potential temperature (in K). Right panels show anomalous zonal wind at $26^{\circ} \mathrm{N}$ (shading, in $\mathrm{m} \mathrm{s}^{-1}$ ) for (b) the Control-FlatMex GCM and (d) the stationary wave model, with isentropes plotted in blue ( $5 \mathrm{~K}$ contour interval) and orography masked in white; the total zonal wind (basic state plus response to orography) is contoured in orange, with a contour interval of $2 \mathrm{~m} \mathrm{~s}^{-1}$, negative contours omitted, and the zero contour in bold. Note the total wind is eastward at low levels west of the SMO. Streamfunction has been normalized by the gravitational acceleration and the value of the Coriolis parameter at $45^{\circ} \mathrm{N}$, giving it the units of geopotential height. 

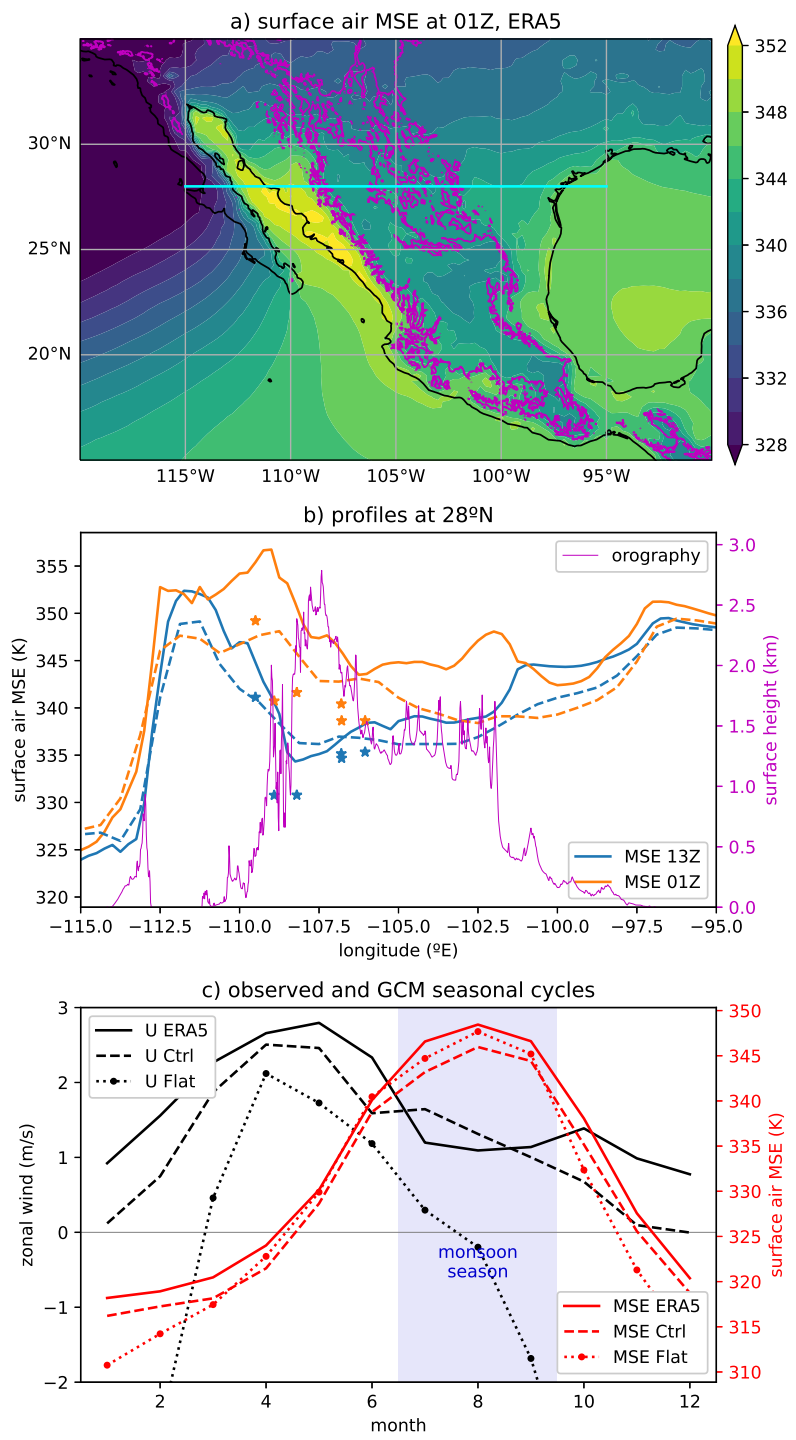

Figure 3. Diurnal and seasonal cycles in the North American monsoon. (a) Observed surface air moist static energy (MSE; shading, from ERA5) at the time of day when MSE peaks (6 pm local time in western Mexico) and orography (1.5 km surface height contoured in magenta). Blue line marks the location of the zonal section of surface air MSE and surface height shown in (b), which illustrates the migration of peak MSE from the Gulf of California at 6 am (blue) toward the western Sierra Madre at $6 \mathrm{pm}$ (orange) local time. In (b), MSE is from the ERA5 (solid lines) and MERRA2 (dashed lines) reanalyses ${ }^{41}$, and from station data (stars), indicating robustness in the amplitude of the diurnal cycle and the rough location of maxima despite observational uncertainty. (c) Seasonal cycle of surface air MSE averaged over the NAM region (red lines) and near-surface zonal wind averaged over and upstream (i.e., west) of that region (black lines; see Supplementary Fig. S7 for averaging regions). Note the large reduction in eastward flow and small increase in MSE during monsoon season when orography is flattened. 

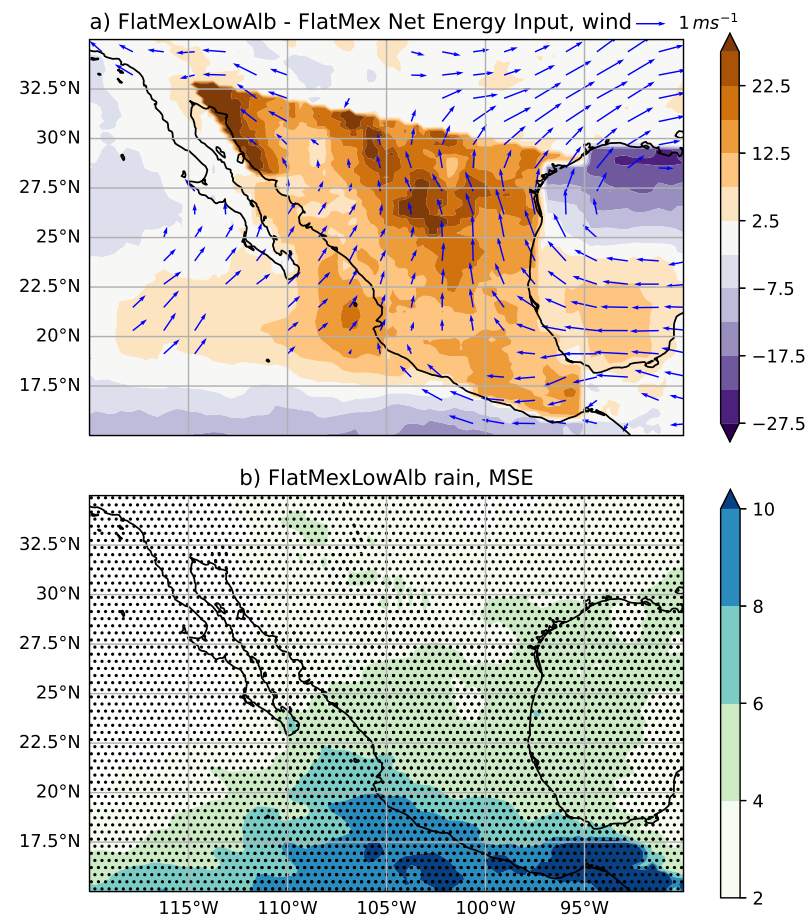

Figure 4. Response to a pure thermal forcing. (a) Anomalies, produced by imposing a reduced surface albedo in the GCM with flattened orography over Mexico, in $700 \mathrm{hPa}$ horizontal wind (vectors) and net energy input through the top and bottom boundaries of the atmosphere (shading, $\mathrm{W} \mathrm{m}^{-2}$ ). (b) Total precipitation $\left(\mathrm{mm} \mathrm{day}^{-1}\right.$ ) and the extent of the region with high surface air moist static energy (defined as a 2-meter value larger than $345 \mathrm{~kJ} \mathrm{~kg}^{-1}$; black stippling) in the same GCM with flattened orography and reduced albedo. Compare stippling in (b) with red shading in Fig. 1d to infer the MSE response to the thermal forcing, and compare shading in (b) with shading in Fig. 1c to infer the precipitation response. 


\section{Supplementary Files}

This is a list of supplementary files associated with this preprint. Click to download.

- BoosPascaleSupplementary20210510submitted.pdf 